CHRONIC OBSTRUCTIVE PULMONARY DISEASE

\title{
Severe acute exacerbations and mortality in patients with chronic obstructive pulmonary disease
}

\author{
J J Soler-Cataluña, M Á Martínez-García, P Román Sánchez, E Salcedo, M Navarro, \\ R Ochando
}

See end of article for authors' affiliations

Correspondence to: Dr J J Soler-Cataluña Unidad de Neumología, Servicio de Medicina Interna, Hospital General de Requena, Paraje Casablanca s/n 46340, Requena (Valencia), Spain; ïsoler@telefonica. net

Received 13 January 2005 Accepted 3 July 2005

Published Online First 29 July 2005
Background: Patients with chronic obstructive pulmonary disease (COPD) often present with severe acute exacerbations requiring hospital treatment. However, little is known about the prognostic consequences of these exacerbations. A study was undertaken to investigate whether severe acute exacerbations of COPD exert a direct effect on mortality.

Methods: Multivariate techniques were used to analyse the prognostic influence of acute exacerbations of COPD treated in hospital (visits to the emergency service and admissions), patient age, smoking, body mass index, co-morbidity, long term oxygen therapy, forced spirometric parameters, and arterial blood gas tensions in a prospective cohort of 304 men with COPD followed up for 5 years. The mean (SD) age of the patients was 71 (9) years and forced expiratory volume in 1 second was 46 (17)\%.

Results: Only older age (hazard ratio (HR) $5.28,95 \% \mathrm{Cl} 1.75$ to 15.93), arterial carbon dioxide tension (HR 1.07, 95\% Cl 1.02 to 1.12), and acute exacerbations of COPD were found to be independent indicators of a poor prognosis. The patients with the greatest mortality risk were those with three or more acute COPD exacerbations (HR 4.13,95\% Cl 1.80 to 9.41).

Conclusions: This study shows for the first time that severe acute exacerbations of COPD have an independent negative impact on patient prognosis. Mortality increases with the frequency of severe exacerbations, particularly if these require admission to hospital.

\section{C} hronic obstructive pulmonary disease (COPD) is a chronic illness with great social, health care, and cause of death after neoplastic disease, ischaemic heart disease, and cerebrovascular diseases. ${ }^{1}$ However, of all these illnesses, only COPD mortality has increased in recent years and by the year 2020 it is expected to become the third leading cause of death in the world. ${ }^{2}$

Different authors have investigated the predictive factors associated with increased COPD mortality. Forced expiratory volume in one second $\left(\mathrm{FEV}_{1}\right),{ }^{3}{ }^{4}$ patient age, ${ }^{4}$ hypoxaemia, hypercapnia, ${ }^{3}$ co-morbidity, ${ }^{36}$ pulmonary hypertension, and body mass index $(\mathrm{BMI})^{8}$ are some of the adverse prognostic variables most commonly cited in the literature. In recent years other risk factors have also been described including dyspnoea, ${ }^{9}$ health related quality of life (HRQoL), ${ }^{10}$ and exercise tolerance. ${ }^{11} \mathrm{~A}$ new multifactorial prognostic classification-the BODE (BMI, airflow obstruction, dyspnoea, exercise performance) index-has recently been proposed. This classification, proposed by Celli et al, ${ }^{12}$ stresses the multicomponent nature of COPD and addresses not only its pulmonary consequences but also the systemic manifestations of the disease. None of these studies has specifically examined the prognostic influence of acute exacerbations of COPD, despite the fact that they have a very relevant role in the natural course of the disease. It has been estimated that COPD patients suffer 1-4 exacerbations per year. ${ }^{13}$ Such decompensation episodes have an important impact on $\mathrm{HRQOL}^{14}$ and generate great healthcare burdens and economic costs. Between $1 \%$ and $2 \%$ of all emergency service visits and $10 \%$ of all medical admissions are attributable to acute exacerbations of COPD. ${ }^{15}$ Nearly $60 \%$ of the global cost of the disease is associated with exacerbation episodes, particularly severe acute exacerbations requiring admission to hospital. ${ }^{16}$ Despite this strong impact, however, very few series have examined the specific influence of acute exacerbations of COPD on patient mortality.

Some authors ${ }^{17-20}$ have recently detected a high mortality rate following hospital admission, ranging from $22-43 \%$ after 1 year to $36-49 \%$ after 2 years, depending on the severity of the COPD patients studied. These series have specifically investigated the risk factors associated with mortality after hospitalisation. Again, advanced patient age, ${ }^{17}{ }^{19}{ }^{20} \mathrm{PaCO}_{2},{ }^{19} \mathrm{PaO}_{2} / \mathrm{FiO}_{2},{ }^{17} \mathrm{BMI},{ }^{17}$ serum albumin, ${ }^{17}$ co-morbidity, ${ }^{18} 20$ cor pulmonale, ${ }^{17} 20$ and functional status ${ }^{17}{ }^{18}$ have been identified as prognostic variables. These results suggest that the principal determinant of death following hospitalisation is the baseline severity of the diseasethat is, the greater the severity of COPD, the greater the likeliness of hospital admission and also of death. However, to date no study has examined the possibility that acute exacerbations of COPD may intrinsically exert a negative effect upon patient prognosis independently of the baseline severity of the disease.

This study investigates whether severe acute exacerbations of COPD - that is, exacerbation episodes requiring hospital management-exert a direct and independent effect on the survival of patients with COPD.

\section{METHODS}

\section{Subjects}

A prospective study was performed in a cohort of 304 male patients with stable COPD. The patients were recruited in the course of 1998 and followed for 5 years. The general characteristics of the cohort and the selection criteria used are described in detail elsewhere. ${ }^{15}$ Briefly, the diagnosis of COPD was based on current or past smoking history $(>20$

Abbreviations: BMI, body mass index; COPD, chronic obstructive pulmonary disease; $\mathrm{FEV}_{1}$, forced expiratory volume in 1 second; $\mathrm{FVC}$, forced vital capacity; LTOT, long term oxygen therapy; $\mathrm{PaO}_{2}, \mathrm{PaCO}_{2}$, arterial oxygen and carbon dioxide tensions 
pack years), clinical evaluation, and pulmonary function testing showing airflow obstruction $\left(\mathrm{FEV}_{\mathrm{l}} / \mathrm{FVC}<70\right)$ with a change in $\mathrm{FEV}_{1}$ of less than $200 \mathrm{ml}$ and $12 \%$ in the bronchodilator test. ${ }^{21}$ The severity of the disease was established according to the latest GOLD criteria. ${ }^{22}$ Patients previously diagnosed with bronchial asthma, bronchiectasis, cystic fibrosis, upper airways obstruction, or bronchiolitis related to systemic pathology were excluded. All included patients were required to be in a stable phase of the disease, without acute exacerbations of COPD in the month preceding the study.

\section{Study protocol}

Age, sex, smoking history, co-morbidity, BMI, long term oxygen therapy (LTOT), forced spirometric parameters, and arterial blood gas data were collected in all patients. Comorbidity was quantified according to the index of Charlson et al. ${ }^{23}$ This index has been developed to predict mortality among patients with chronic diseases. BMI was calculated by dividing patient body weight (in $\mathrm{kg}$ ) by the square of height (in $\mathrm{m}^{2}$ ). $\mathrm{FEV}_{1}$ and forced vital capacity (FVC) were determined by forced spirometry (Autospiro AS-600, Minato Medical Science SA, Japan), following the guidelines established by the Spanish Society of Pneumology and Chest Surgery (Sociedad Española de Neumología and Cirugía Torácica, SEPAR). ${ }^{24}$ The $\mathrm{FEV}_{1}$ and FVC results are expressed as percentages of the adult reference values. ${ }^{25}$ Postbronchodilator $\mathrm{FEV}_{1}$ was used as airflow limitation index because it is regarded as a better predictor of mortality than prebronchodilator $\mathrm{FEV}_{1} \cdot{ }^{4}$

\section{Exacerbations}

A severe acute exacerbation of COPD was defined as any sustained increase in respiratory symptomatology compared with the baseline situation requiring modification of regular medication and hospital treatment. ${ }^{26}$ A prospective registry was made of all exacerbation episodes requiring hospital management during the year of the study. The patients were divided into three groups according to the number of acute exacerbations recorded: group A (no acute exacerbations); group B (1-2 acute exacerbations); and group C ( $\geqslant 3$ acute exacerbations).

\section{Statistical analysis}

Descriptive statistics were used to describe the study population at baseline. The comparison of means among the three study groups was based on analysis of variance, with $\chi^{2}$ testing and Bonferroni correction for comparison of the proportions. Survival of all subjects was assessed after 5 years and all-cause mortality was evaluated. The starting date was taken as 1 January 1998 and the termination date was 31 December 2002. We first conducted univariate analyses based on the Cox proportional hazards model using each of the potential predictors of respiratory mortality as independent variables and survival as the dependent variable. ${ }^{27}$ Survival curves for the three groups were estimated by the Kaplan-Meier product limit method and compared using the log rank test. ${ }^{28}$ Independent variables associated with respiratory mortality with $\mathrm{p}<0.15$ in the univariate analysis were then incorporated into a multivariate analysis also based on the Cox proportional model. An interaction term between the variables and time was introduced into the model to analyse risk proportionality. All statistical analyses were carried out using a statistical software package (SPSS for Windows, version 11.5; SPSS Inc, Chicago, IL, USA). A p value of $<0.05$ was considered significant.

\section{RESULTS}

\section{Subject characteristics}

Of the 320 cases in the initial cohort, two (0.6\%) were excluded because of an absence of smoking history and 11 (3.4\%) were excluded because they had a smoking history of $<20$ pack years. The only women in the study $(\mathrm{n}=3,0.9 \%)$ were also excluded to increase homogeneity. The study therefore comprised a total of 304 male patients diagnosed with COPD (mean age 71 (9) years). The baseline characteristics of the patients are shown in table l. One hundred and sixty three cases $(53.6 \%)$ had suffered no acute exacerbations (group A); 105 (34.5\%) had two or less acute exacerbations, 60 of whom had been admitted to hospital (group B); and 36 (11.8\%) had suffered three or more exacerbations, 29 having been admitted to hospital at least once during the year of the study (group C). In general terms, the patients belonging to group $\mathrm{C}$ were older and had more advanced disease, with lower $\mathrm{FEV}_{1}, \mathrm{FVC}$, and $\mathrm{PaO}_{2}$ and higher $\mathrm{PaCO}_{2}$ (table 1).

Table 1 Mean (SD) baseline characteristics of study patients $(n=304)$

\begin{tabular}{|c|c|c|c|c|c|}
\hline & $\begin{array}{l}\text { All patients } \\
(n=304)\end{array}$ & $\begin{array}{l}\text { Group A } \\
(n=163,53.6 \%)\end{array}$ & $\begin{array}{l}\text { Group B } \\
(n=105,34.5 \%)\end{array}$ & $\begin{array}{l}\text { Group C } \\
(n=36,11.8 \%)\end{array}$ & $p$ value \\
\hline Age (years) & $71(9)$ & $69(10)$ & 72 (7) & $71(9)$ & 0.001 \\
\hline BMI $\left(\mathrm{kg} / \mathrm{m}^{2}\right)$ & $28.3(5.1)$ & $28.8(5.4)$ & $27.7(4.7)$ & $27.7(4.1)$ & 0.350 \\
\hline Co-morbidity index & $0.95(1.34)$ & $0.90(1.30)$ & $0.92(1.21)$ & $1.23(1.82)$ & 0.422 \\
\hline Co-morbidity, n (\%) & & & & & 0.765 \\
\hline 0 & 145 (47.7\%) & 80 (48.8\%) & $48(46.2 \%)$ & $17(47.2 \%)$ & \\
\hline 1 & 91 (29.9\%) & $47(28.6 \%)$ & 35 (33.6\%) & $9(25.0 \%)$ & \\
\hline$\geqslant 2$ & $68(22.4 \%)$ & $37(22.6 \%)$ & $21(20.2 \%)$ & $10(27.8 \%)$ & \\
\hline $\mathrm{FEV}_{1}(\mathrm{l})$ & $1.18(0.64)$ & $1.29(0.76)$ & $1.11(0.45)$ & $0.88(0.33)$ & 0.002 \\
\hline $\mathrm{FEV}_{1}(\%$ predicted $)$ & $46.4(17.2)$ & $49.2(16.6)$ & $45.9(17.6)$ & $34.5(13.6)$ & $<0.001$ \\
\hline GOLD classification, n (\%) & & & & & $<0.001$ \\
\hline Stage I & $20(6.6 \%)$ & $15(9.2 \%)$ & $5(4.8 \%)$ & - & \\
\hline Stage II & $109(35.9 \%)$ & $66(40.5 \%)$ & $38(36.2 \%)$ & $5(13.9 \%)$ & \\
\hline Stage III & $102(33.6 \%)$ & $57(35.0 \%)$ & $33(31.4 \%)$ & $12(33.3 \%)$ & \\
\hline Stage IV & $73(24.0 \%)$ & $25(15.3 \%)$ & $29(27.6 \%)$ & $19(52.8 \%)$ & \\
\hline FVC (I) & $2.22(0.67)$ & $2.34(0.72)$ & $2.12(0.62)$ & $1.93(0.62)$ & 0.002 \\
\hline FVC (\% predicted) & $69.4(19.1)$ & $72.0(19.3)$ & $68.0(18.7)$ & $61.1(17.3)$ & 0.010 \\
\hline $\mathrm{PaO}_{2}(\mathrm{kPa})$ & $8.8(1.6)$ & $9.1(1.5)$ & $8.6(1.5)$ & $8.0(1.6)$ & $<0.001$ \\
\hline $\mathrm{PaCO}_{2}(\mathrm{kPa})$ & $5.8(1.0)$ & $5.7(0.8)$ & $5.9(1.0)$ & $6.2(1.4)$ & 0.019 \\
\hline
\end{tabular}

$\mathrm{BMI}$, body mass index; $\mathrm{FEV}_{1}$, forced expiratory volume in 1 second; $\mathrm{FVC}$, forced vital capacity; $\mathrm{PaO}_{2}, \mathrm{PaCO}_{2}$, arterial oxygen and carbon dioxide tensions. Group A, no acute exacerbations of COPD; group B, 1-2 acute exacerbations of COPD (emergency visits or hospital admissions); group C, $\geqslant 3$ acute exacerbations of COPD. 


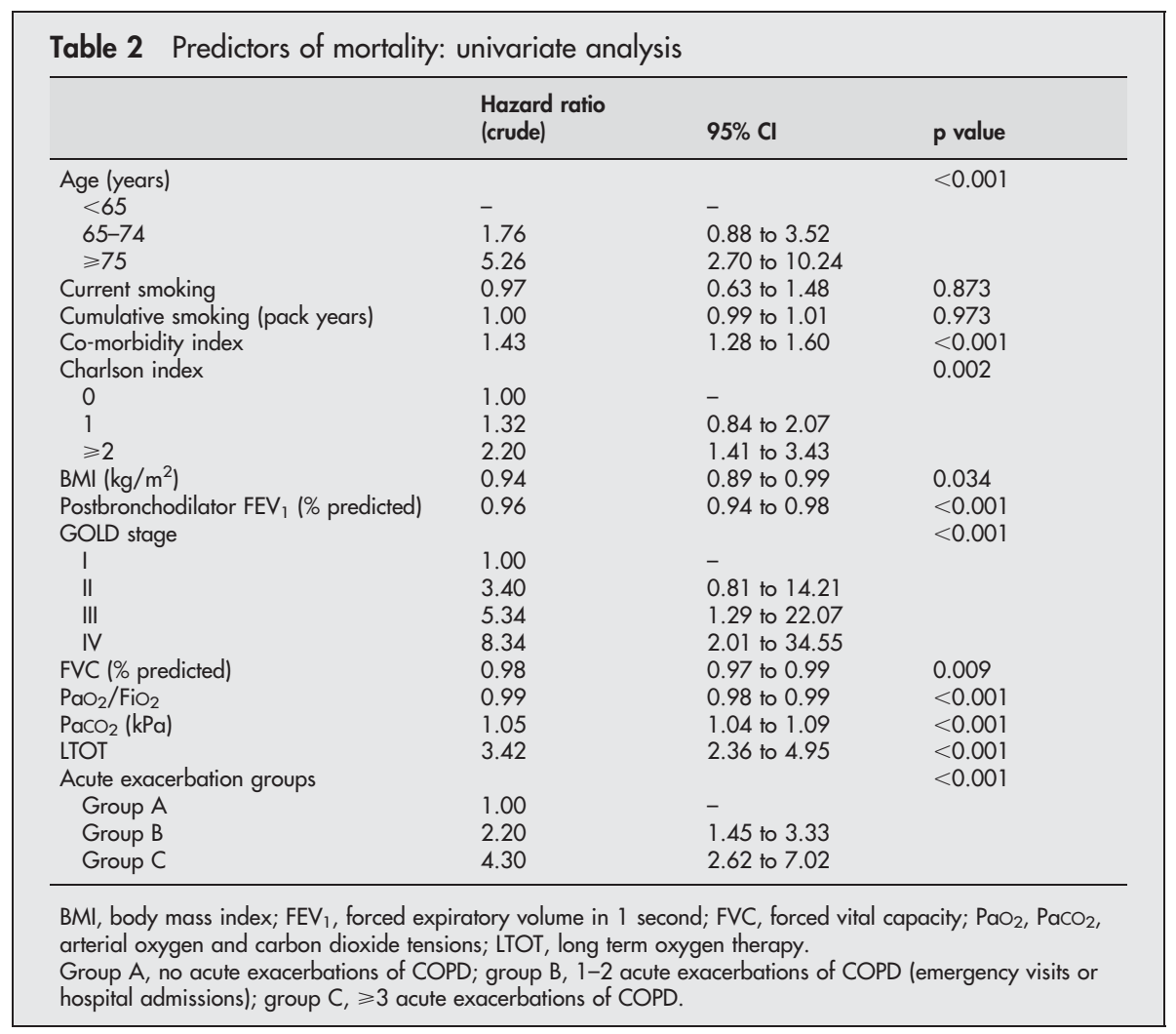

\section{Univariate survival analysis}

A total of 116 deaths (38.2\%) were recorded; 78 (25.7\%) were due to respiratory causes and $38(12.5 \%)$ died of different causes ( $12(3.9 \%)$ from cardiovascular disease, seven $(2.3 \%)$ from cerebrovascular disease, 11 (3.6\%) neoplasms, and six $(2.0 \%)$ from other diseases). In two cases $(0.7 \%)$ the cause of death was unknown. Thirty two patients were lost in the course of the 5 year follow up period (follow up rate $89.5 \%$ ). Table 2 shows the influence on the prognosis of the variables included in the univariate analysis.

Figure 1 shows the survival curves according to the frequency of acute exacerbations of COPD. Patients with frequent exacerbations (group $\mathrm{C}$ ) had the highest mortality rate $(p<0.001)$ with a risk of death 4.30 times greater $(95 \%$
CI 2.62 to 7.02 ) than for patients requiring no hospital management (group A). Patients in group B also showed significant differences in survival compared with group A (hazard ratio (HR) $2.20,95 \%$ CI 1.45 to 3.33 ).

Eighty nine patients (29.3\%) were admitted to hospital at least once during 1998. Mortality in this group after 12, 24, 36,48 , and 60 months was $11.6 \%, 25.9 \%, 40.2 \%, 46.6 \%$ and $55.2 \%$, respectively. Patients with only one hospital admission had poorer survival than those with no acute exacerbations of COPD (HR 2.94, 95\% CI 1.82 to 4.72 ) or than patients with visits to the emergency service without admission. The lowest survival was observed in the group with readmissions (HR 4.31, 95\% CI 2.70 to 6.88; fig 2).

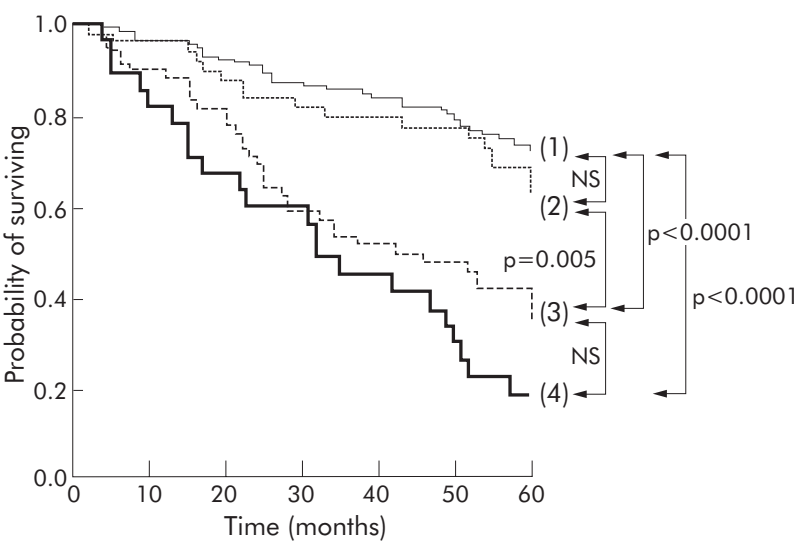

Figure 2 Kaplan-Meier survival curves by severity of exacerbations in patients with COPD: (1) no acute exacerbations of COPD; (2) patients with acute exacerbations of COPD requiring emergency service visits without admission; (3) patients with acute exacerbations of COPD requiring one hospital admission; (4) patients with readmissions.
Figure 1 Kaplan-Meier survival curves by frequency of exacerbations in patients with COPD: group $A$, patients with no acute exacerbations of COPD; group $B$, patients with 1-2 acute exacerbations of COPD requiring hospital management; group $C$, patients with $\geqslant 3$ acute exacerbations of COPD. 


\section{Interaction and confounding by variables}

No significant interaction was observed among the different study variables and the prognostic effect of acute exacerbations of COPD. The confounding variables of this association were age, $\mathrm{FEV}_{1} \%, \mathrm{PaO}_{2} / \mathrm{FiO}_{2}$, and LTOT. After adjusting the model for each of these variables, the presence of acute exacerbations of COPD continued to appear as an independent prognostic variable in all cases (table 3 ).

\section{Multivariate analysis of survival}

Age, co-morbidity index, $\mathrm{BMI}, \mathrm{FEV}(\%)$, $\mathrm{FVC}(\%), \mathrm{PaO}_{2} / \mathrm{FiO}_{2}$, $\mathrm{PaCO}_{2}$, LTOT, and the number of acute exacerbations of COPD during the year of the study were the variables included in the Cox multiple regression model. In this multivariate model, the frequency of acute exacerbations, age, and Charlson index were analysed as categorical variables. The risk proportionality test proved non-significant; hazards ratios were unchanged over time. Table 4 shows the regression model adjusted for all the significant prognostic variables. Severe acute exacerbations of COPD, particularly when multiple, were one of the most relevant independent adverse prognostic variables with an adjusted mortality risk four times greater than for patients without acute exacerbations. Older age and $\mathrm{PaCO}_{2}$ also had a deleterious effect on survival.

\section{DISCUSSION}

To our knowledge, this is the first study to show that severe exacerbations requiring hospital management are independently associated with all-cause mortality in patients with COPD. Our results suggest that the mortality risk increases with the frequency of severe acute exacerbations. The maximum mortality risk occurred in those individuals presenting with $\geqslant 3$ exacerbations, particularly if they required hospitalisation. We consider that these observations are very important since the frequency of acute exacerbations of COPD is potentially modifiable.

Different studies have reported a high mortality rate after admission to hospital with acute exacerbations of COPD. ${ }^{17-20}$ In the most important series published to date, Connors et al ${ }^{17}$ recorded an in-hospital mortality rate of $11 \%$ in patients with acute hypercapnic respiratory failure. During subsequent follow up the subjects who survived the hospital admission had mortality rates of $43 \%$ and $49 \%$ after 1 and 2 years, respectively. Other series with less severe exacerbations have also reported a considerable number of deaths after admission, although to a somewhat lesser degree. Almagro et al, ${ }^{18}$ in a series of 135 patients, reported respiratory mortality figures of $22 \%$ and $35.6 \%$ after 1 and 2 years, respectively. Groenewegen et al ${ }^{19}$ likewise found a $23 \%$ mortality rate after 1 year in a series of 171 patients. The number of deaths is even higher in patients with COPD requiring mechanical ventilation. Seneff et $a l^{29}$ reported an in-hospital mortality rate of $24 \%$, with mortality rates after hospital discharge increasing to $59 \%$ after 1 year.

Based on these findings, it has been suggested that admission to hospital for acute exacerbations of COPD allows the identification of a subgroup of patients with a poorer prognosis. ${ }^{18}$ The most widely accepted hypothesis relates baseline severity of the disease to an increased likeliness of an exacerbation-a situation which, in turn, would explain the poorer survival recorded after hospitalisation. This hypothesis is reinforced by identification of the risk factors associated with mortality following admission, since the variables defining the baseline severity of COPD—such as advanced patient age, ${ }^{17}{ }^{10}$ hypoxaemia, ${ }^{17}$ hypercapnia, ${ }^{19}$

Table 3 Prognostic value of frequency of acute exacerbations of COPD (AECOPD) adjusted by confounders

\begin{tabular}{|c|c|c|c|}
\hline & $\begin{array}{l}\text { Hazard ratio } \\
\text { (adjusted) }\end{array}$ & $95 \% \mathrm{Cl}$ & $\mathrm{p}$ value \\
\hline \multicolumn{4}{|c|}{ AECOPD adjusted by age } \\
\hline Age (years) & & & $<0.001$ \\
\hline$<65$ & Reference & - & \\
\hline $65-74$ & 1.62 & 0.80 to 3.25 & \\
\hline$\geqslant 75$ & 4.52 & 2.31 to 8.83 & \\
\hline AECOPD groups & & & $<0.001$ \\
\hline Group A & Reference & - & \\
\hline Group B & 1.93 & 1.27 to 2.93 & \\
\hline Group C & 3.64 & 2.22 to 5.98 & \\
\hline \multicolumn{4}{|c|}{ AECOPD adjusted by $\mathrm{FEV}_{1} \%$} \\
\hline $\mathrm{FEV}_{1} \%$ (predicted) & 0.99 & 0.97 to 0.99 & 0.028 \\
\hline AECOPD groups & & & $<0.001$ \\
\hline Group $A$ & Reference & - & \\
\hline Group B & 2.08 & 1.33 to 3.25 & \\
\hline Group C & 3.45 & 1.99 to 5.99 & \\
\hline \multicolumn{4}{|c|}{ AECOPD adjusted by $\mathrm{PaO}_{2} / \mathrm{FiO}_{2}$} \\
\hline $\mathrm{PaO}_{2} / \mathrm{FiO}_{2}$ & 0.99 & 0.990 to 0.997 & $<0.001$ \\
\hline AECOPD groups & & & $<0.001$ \\
\hline Group A & Reference & - & \\
\hline Group B & 2.12 & 1.37 to 3.29 & \\
\hline Group C & 3.69 & 2.18 to 6.25 & \\
\hline \multicolumn{4}{|c|}{ AECOPD adjusted by LTOT } \\
\hline LTOT & 2.72 & 1.84 to 4.02 & $<0.001$ \\
\hline \multicolumn{4}{|l|}{ AECOPD groups } \\
\hline Group A & Reference & - & $<0.001$ \\
\hline Group B & 1.74 & 1.14 to 2.67 & \\
\hline Group C & 2.92 & 1.74 to 4.88 & \\
\hline
\end{tabular}

$\mathrm{AECOPD}$, acute exacerbations of $\mathrm{COPD} ; \mathrm{FEV}$, forced expiratory volume in 1 second; $\mathrm{PaO}_{2}$, arterial oxygen tension; $\mathrm{FiO}_{2}$, fractional inspired oxygen; LTOT, long term oxygen therapy.

Group A, no acute exacerbations of COPD; group B, 1-2 acute exacerbations of COPD (emergency visits or hospital admissions); group $C, \geqslant 3$ acute exacerbations of COPD. 


\begin{tabular}{|c|c|c|c|}
\hline & $\begin{array}{l}\text { Hazard ratio } \\
\text { (adjusted) }\end{array}$ & $95 \% \mathrm{Cl}$ & p value \\
\hline \multicolumn{3}{|l|}{ Age (years) } & \multirow[t]{4}{*}{0.001} \\
\hline$<65$ & Reference & - & \\
\hline $65-74$ & 1.92 & 0.64 to 5.25 & \\
\hline$\geqslant 75$ & 5.28 & 1.75 to 15.93 & \\
\hline \multicolumn{3}{|l|}{ Charlson index } & \multirow[t]{4}{*}{0.101} \\
\hline 0 & Reference & - & \\
\hline 1 & 1.17 & 0.59 to 2.29 & \\
\hline$\geqslant 2$ & 2.23 & 1.06 to 4.69 & \\
\hline BMI $\left(\mathrm{kg} / \mathrm{m}^{2}\right)$ & 0.96 & 0.89 to 1.03 & 0.245 \\
\hline $\mathrm{FEV}_{1}$ (\% predicted) & 0.97 & 0.96 to 1.03 & 0.810 \\
\hline FVC (\% predicted) & 0.97 & 0.97 to 1.02 & 0.695 \\
\hline $\mathrm{PaO}_{2} / \mathrm{FiO}_{2}$ & 1.00 & 0.99 to 1.01 & 0.374 \\
\hline $\mathrm{PaCO}_{2}$ & 1.07 & 1.02 to 1.12 & 0.006 \\
\hline LTOT & 1.95 & 0.93 to 4.12 & 0.078 \\
\hline \multicolumn{3}{|l|}{ Exacerbation groups } & \multirow[t]{4}{*}{0.003} \\
\hline Group A & Reference & - & \\
\hline Group B & 2.00 & 1.01 to 3.98 & \\
\hline Group C & 4.13 & 1.80 to 9.45 & \\
\hline \multicolumn{4}{|c|}{$\begin{array}{l}\mathrm{BMI} \text {, body mass index; } \mathrm{FEV}_{1} \text {, forced expiratory volume in } 1 \text { second; } \mathrm{FVC} \text {, forced vital capacity; } \mathrm{PaO}_{2}, \mathrm{PaCO}_{2} \text {, } \\
\text { arterial oxygen and carbon dioxide tensions; Fio } 2 \text {, fractional inspired oxygen; } \mathrm{LTOT} \text {, long term oxygen therapy. } \\
\text { Group } \mathrm{A} \text {, no acute exacerbations of COPD; group } \mathrm{B}, 1-2 \text { acute exacerbations of COPD (emergency visits or } \\
\text { hospital admissions); group C, } \geqslant 3 \text { acute exacerbations of COPD. }\end{array}$} \\
\hline
\end{tabular}

$\mathrm{BMI},{ }^{17} \mathrm{CO}$-morbidity, ${ }^{18}{ }^{20}$ cor pulmonale, ${ }^{17}{ }^{20}$ or sustained oral corticosteroid treatment ${ }^{19}$-have been described as mortality predicting factors after admission.

We also observed a high mortality among patients requiring admission to hospital, with a crude mortality risk 2.94-fold greater than in subjects without acute exacerbations requiring hospital admission. However, unlike in the earlier series, our results indicate that acute exacerbations of COPD requiring hospital management per se increase the risk of death independently of other classical prognostic factors such as $\mathrm{FEV}_{1}$, age, BMI, co-morbidity or respiratory failure. Increased mortality is particularly observed in cases requiring admission to hospital and less so in patients requiring emergency visits without admission to hospital, which suggests that the severity of the exacerbation influences mortality. However, exacerbation recurrence also has an important effect on prognosis since the risk was particularly high for patients with three or more acute exacerbations and for those who had been readmitted. A recent prospective study following patients with severe COPD suggests that lung function deteriorates more rapidly in those with more frequent exacerbations. ${ }^{30}$ This effect appears to be small, however, with a mean decline in $\mathrm{FEV}_{1}$ of $8 \mathrm{ml} /$ year in individuals experiencing exacerbations more often than the median compared with those who had exacerbations less often than the median. Although not specifically designed to evaluate exacerbations, the Lung Health Study noted a similar effect of exacerbations on the rate of decline of $\mathrm{FEV}_{1}$ in smokers but no effect in ex-smokers. ${ }^{31}$ Both studies suggest that exacerbations accelerate the loss of lung function, this being an indirect indicator of mortality. However, to our knowledge, this is the first study to identify an intrinsic deleterious effect of acute exacerbations on patient survival.

The reasons underlying this increase in risk following acute exacerbations of COPD are not clear. Our study was not specifically designed to examine this, but the results suggest that, as the severity of exacerbations increases (regardless of the baseline severity of the disease), the risk of death also increases. In fact, patients admitted to hospital had higher mortality rates than those seen in the emergency service who did not require admission to hospital (fig 2). Similar results have been reported by other authors. In the series published by Connors et $\mathrm{al}^{17}$ the most important predictor of 6 month survival was the overall severity of illness on day 3 of the hospital stay as measured by the acute physiology component of the APACHE score. Blood gas values on hospital admission-another measure of acute abnormality—have also been reported as an independent predictor of survival. ${ }^{17-20}$ Other aspects intrinsically related to acute COPD exacerbations may also be implicated in the survival of these patients. Fuso et $a l^{20}$ in a retrospective series, showed that the variables reflecting heart dysfunction during exacerbations_-such as atrial fibrillation or ventricular arrhythmias-are important determinants of mortality risk. Connors et al ${ }^{17}$ likewise observed that patients presenting with congestive heart failure as the cause of the acute COPD exacerbation suffered increased mortality. In contrast, an infectious aetiology of the acute exacerbation does not seem to be a determinant of increased mortality. ${ }^{17} 18$

One of the most attractive aetiological hypotheses relates inflammation (pulmonary or systemic) triggered during an acute exacerbation to patient survival. Donaldson et al ${ }^{32}$ have recently shown that the severity of exacerbations increases over time, as does sputum purulence, which suggests more inflammation in patients with more severe exacerbations. In our study we only analysed acute exacerbations which were sufficiently serious to require hospital treatment. Therefore, in accordance with the results of Donaldson $\mathrm{el} \mathrm{al}^{32}$ it is possible that our study patients may have had greater inflammation. A group of British investigators has also shown a relationship between airway inflammation and the frequency of exacerbations in patients with COPD. ${ }^{33} 34$ According to these authors, patients with frequent exacerbations have an increased bacterial load in their airways in the stable state. This lower airway bacterial load is associated with increased airway inflammation and an accelerated decrease in $\mathrm{FEV}_{1}$, an indirect but potent mortality indicator.

Poorer survival among patients with frequent acute COPD exacerbations is currently the subject of debate. In a Dutch series $^{19}$ the authors recorded no differences in survival rates between those who had been readmitted and those who had not been readmitted to hospital. In contrast, Connors et al, ${ }^{17}$ in a univariate analysis, observed an increase in mortality associated with readmission. Mortality after 6 months among patients readmitted one, two or more times was $27 \%, 31 \%$ and $36 \%$, respectively, while those requiring no readmission had a mortality rate of $21 \%(p=0.004)$. More 
recently, a Spanish multivariate study ${ }^{18}$ reported a 1.85 -fold greater mortality rate among readmitted subjects after adjusting for other predictive variables. We also found that patients with multiple acute exacerbations admitted to hospital or seen in the emergency service had a markedly greater mortality risk and, after adjusting for different prognostic factors, mortality in these patients was 4.1-fold greater than in those with no acute COPD exacerbations. These results could support the inflammatory hypothesis whereby, as the frequency of severe acute exacerbations increases, inflammation and mortality also increase. However, we did not assess pulmonary or systemic inflammation so further studies in this direction are needed.

To date, the only treatments that have been shown to improve survival in COPD patients have been smoking cessation $^{35}$ and oxygen therapy in subjects with respiratory failure. ${ }^{5}$ If our results are confirmed, treatments capable of reducing the frequency of acute exacerbations of COPD could potentially reduce mortality inherent to exacerbations. Some drugs such as inhaled steroids, ${ }^{36}$ inhaled long acting $\beta_{2}$ agonists, ${ }^{37}$ and tiotropium bromide ${ }^{38}$ have resulted in a significant reduction in the number of exacerbations. This reduction is associated with a marked improvement in HRQoL, ${ }^{36-38}$ and confirmation of our results might suggest that this treatment could also contribute to a reduction in mortality. In a recent pharmacoepidemiological study Soriano $\mathrm{et} \mathrm{l}^{39}$ found that patients treated with a combination of fluticasone and salmeterol had better survival than those receiving monotherapy. An important multicentre study is currently underway to assess the impact of this combined treatment on patient survival. ${ }^{40}$ If our results are confirmed, other management strategies such as measures to combat the high therapeutic failure rate or early treatment could also afford benefit in terms of survival.

Our study has some limitations. Firstly, the prognostic influence of acute exacerbations of COPD requiring hospital management was analysed and it is not clear whether other less severe exacerbation episodes could also exert a prognostic influence. Secondly, although we have attempted to incorporate the prognostic variables most commonly cited in the literature, some parameters that have not been examined (such as the degree of dyspnoea, HRQoL, exercise tolerance, or pulmonary artery pressure) could also interact with exacerbations and their prognostic repercussions. Nevertheless, in an earlier study ${ }^{41}$ in which we considered some of these variables, hospital admission as an expression of severe acute exacerbations was likewise shown to be an independent predictive variable. Another limitation of our study is the cross sectional data collection. Although most studies adopt this same design, longitudinal data (changes in treatment, impairment of lung function, loss of muscle mass, etc), which could equally condition mortality and interact with future exacerbations, were not available. Lastly, we lack detailed data on the acute exacerbations such as clinical aetiology and treatment, so no in-depth evaluation can be made of the causes underlying their future course. The aim of our study was to draw attention to the prognostic role of acute exacerbations of COPD per se, rather than to define the aetiopathogenic mechanisms associated with the increased mortality rate of such exacerbations. Further studies are needed which are designed specifically to address this matter.

In conclusion, our results suggest for the first time that severe acute exacerbations of COPD have an independent negative prognostic impact, with mortality increasing with the frequency of severe exacerbations, particularly if these require admission to hospital. If these results are confirmed, a reduction in the number and severity of exacerbations could be regarded as priority objectives in the management of COPD.

\section{Authors' affiliations}

J J Soler-Cataluña, M Á Martínez-García, Hospital General de Requena, Unidad de Neumología, Servicio de Medicina Interna, Requena (Valencia), Spain

P Román Sánchez, E Salcedo, M Navarro, Hospital General de Requena, Servicio de Medicina Interna, Requena (Valencia), Spain R Ochando, Hospital General de Requena, Servicio de Urgencias, Requena (Valencia), Spain

Competing interests : none declared

\section{REFERENCES}

1 World Health Organization. World Health Report. Geneva: World Health Organization, 2000

2 Murray CJL, Lopez AD. Mortality by cause for eight regions of the world: Global Burden of Disease Study. Lancet 1997;349:1269-76.

3 Burrows B, Earle RH. Prediction of survival in patients with chronic airway obstruction. Am Rev Respir Dis 1969;99:865-71.

4 Anthonisen NR, Wright EC, Hodgkin JE. Prognosis in chronic obstructive pulmonary disease. Am Rev Respir Dis 1986;133:14-20.

5 Nocturnal Oxygen Therapy Trial Group. Continuous or nocturnal oxygen therapy in hypoxemic chronic obstructive pulmonary disease: a clinical trial. Ann Intern Med 1980;93:391-8.

6 Incalzi RA, Fuso L, De Rosa M, et al. Co-morbidity contributes to predict mortality of patients with chronic obstructive pulmonary disease. Eur Respir J 1997; 10:2794-800

7 Oswald-Mammosser M, Weitzenblum E, Quoix E, et al. Prognostic factors in COPD patients receiving long-term oxygen therapy. Importance of pulmonary artery pressure. Chest 1995;107:1193-8.

8 Landbo C, Prescott E, Lange $P$, et al. Prognostic value of nutritional sattus in chronic obstructive pulmonary disease. Am J Respir Crit Care Med 1999; 160:1856-61

9 Nishimura K, Izumi T, Tsukino M, et al. Dyspnea is a better predictor of 5-year survival than airway obstruction in patients with COPD. Chest 2002;121:1434-40

10 Domingo-Salvany A, Lamarca R, Ferrer $M$, et al. Health-related quality of life and mortality in male patients with chronic obstructive pulmonary disease. Am J Respir Crit Care Med 2002; 166:680-5.

11 Oga T, Nishimura K, Tsukino M, et al. Analysis of the factors related to mortality in chronic obstructive pulmonary disease. Role of exercise capacity and health status. Am J Respir Crit Care Med 2003; 167:544-9.

12 Celli BR, Cote CG, Marín JM, et al. The body-mass index, airflow obstruction, dyspnea, and exercise capacity index in chronic obstructive pulmonary disease. N Engl J Med 2004;350:1005-12.

13 Miratvilles M, Mayordomo C, Artés M, et al. Treatment of chronic obstructive pulmonary disease and its exacerbations in general practice. Respir Med 1999;93:173-9.

14 Seemungal TAR, Donaldson GC, Paul EA, et al. Effect of exacerbation on quality of life in patients with chronic obstructive pulmonary disease. Am J Respir Crit Care Med 1998;157:1418-22.

15 Soler JJ, Sánchez L, Latorre M, et al. Impacto asistencial hospitalario de la EPOC. Peso específico del paciente con EPOC de alto consumo sanitario. Arch Bronconeumol 2001;37:375-81.

16 Hilleman DE, Dewan N, Malesker M, et al. Pharmacoeconomic evaluation of COPD. Chest 2000;118:1278-85.

17 Connors AF, Dawson NV, Thomas C, et al. Outcomes following acute exacerbation of severe chronic obstructive lung disease. Am J Respir Crit Care Med 1996; 154:959-67.

18 Almagro P, Calbo E, Ochoa de Echagüen A, et al. Mortality after hospitalization for COPD. Chest 2002;121:1441-8.

19 Groenewegen KH, Schols AMWJ, Wouters E. Mortality and mortality-related factors after hospitalization for acute exacerbation of COPD. Chest 2003; 124:459-67.

20 Fuso L, Incalzi RA, Pistelli R, et al. Predicting mortality of patients hospitalized for acutely exacerbated chronic obstructive pulmonary disease. Am J Med 1995;98:272-7.

21 Global Initiative for Chronic Obstructive Lung Disease. Global strategy for the diagnosis, management and prevention of chronic obstructive pulmonary disease, NIH Publication No 2701. NHLBI/WHO Workshop Report. Bethesda, MD: National Heart, Lung and Blood Institute, 2001:1-100.

22 Fabbri LM, Hurd SS, for the GOLD Scientific Committee. Global strategy for the diagnosis, management and prevention of COPD: 2003 update. Eur Respir J 2003;22:1-2

23 Charlson ME, Pompei P, Ales KL, et al. A new method of classifying prognostic comorbidity in longitudinal studies: development and validation. J Chronic Dis 1987:40:373-83.

24 Sanchis J, Casan P, Castillo J, et al. Normativa para la práctica de la espirometría forzada. Arch Bronconeumol 1989;25:132-42.

25 Roca J, Sanchis J, Agustí-Vidal A, et al. Spirometric reference values for a Mediterranean population. Bull Eur Physiopathol Respir 1986;22:217-24.

26 Rodríguez-Roisin R. Toward a consensus definition for COPD exacerbation. Chest 2000;117:398-401s.

27 Cox DR. Regression models and life tables. J R Stat Soc 1972;B34:187-220.

28 Kaplan EL, Meier P. Nonparametric estimation from incomplete observation. J Am Stat Assoc 1969:53:457-81.

29 Seneff MG, Wagner DP, Wagner RP, et al. Hospital and 1-year survival of patients admitted to intensive care units with acute exacerbation of chronic obstructive pulmonary disease. JAMA 1995;274:1852-7. 
30 Donaldson GC, Seemungal TAR, Bhowmik A, et al. Relationship between exacerbation frequency and lung function decline in chronic obstructive pulmonary disease. Thorax 2002;57:847-52.

31 Kanner RE, Anthonisen NR, Connett JE. Lower respiratory illnesses promote FEV(1) decline in current smokers but not exsmokers with mild chronic obstructive pulmonary disease. Am J Respir Crit Care Med 2001;164:358-64.

32 Donaldson GC, Seemungal TAR, Patel IS, et al. Longitudinal changes in the nature, severity and frequency of COPD exacerbations. Eur Respir J 2003;22:931-6.

33 Patel IS, Seemungal TAR, Wiks $M$, et al. Relationship between bacterial colonisation and the frequency, character, and severity of COPD exacerbations. Thorax 2002;57:759-64.

34 Wilkinson TA, Patel IS, Wiks $M$, et al. Airway bacterial load and FEV 1 decline in patients with chronic obstructive pulmonary disease. Am J Respir Crit Care Med 2003; 167:1090-5

35 Scanlon PD, Connett JE, Waller LA, et al. Smoking cessation and lung function in mild-to-moderate chronic obstructive pulmonary disease: the Lung Health Study. Am J Respir Crit Care Med 2000;161:381-90.
36 Burge PS, Calverley PMA, Jones PW et al on behalf of the ISOLDE study investigators: randomised, double blind, placebo controlled study of fluticasone propionate in patients with moderate to severe chronic obstructive pulmonary disease; the ISOLDE trial. BMJ 2000;320:1297-303.

37 Calverley P, Pauwels R, Vestbo J, et al. Combined salmeterol and fluticasone in the treatment of chronic obstructive pulmonary disease: a randomised controlled trial. Lancet 2003;361:449-56.

38 Brusasco V, Hodder R, Miravitlles $M$, et al. Health outcomes following treatment for six months with once daily tiotropium compared with twice daily salmeterol in patients with COPD. Thorax 2003;58:399-404.

39 Soriano JB, Vestbo J, Pride NB, et al. Survival in COPD patients after regular use of fluticasone propionate and salmeterol in general practice. Eur Respir $J$ 2002;20:819-25.

40 Vestbo J, and the TORCH Study Group. The TORCH (Towards a Revolution in COPD Health) survival study protocol. Eur Respir J 2004;24:206-10.

41 Soler JJ, Sánchez L, Martínez MA, et al. Mid-arm muscle area is a better predictor of mortality than body mass index in chronic obstructive pulmonary disease. Chest 2005 (in press).

\section{LUNG ALERT}

The role of erlotinib in advanced NSCLC

$\Delta$ Shepherd FA, Rodrigues Pereira J, Ciuleanu T, et al. Erlotinib in previously treated non-small-cell lung cancer. N Engl J Med 2005;353:123-32

A Tsao M-S, Sakurada A, Cutz JC, et al. Erlotinib in lung cancer-molecular and clinical predictors of outcome. N Engl J Med 2005;353:133-44

$\mathrm{R}$ elapsed advanced non-small cell lung cancer (NSCLC) carries a dismal prognosis and new treatments are particularly welcome. These papers evaluate the use of erlotinib, a tyrosine kinase inhibitor of the epidermal growth factor receptor (EGFR) in patients with NSCLC that has advanced despite prior chemotherapy.

The study was double blind and 731 patients with good performance status who had had at least one prior course of chemotherapy were randomised to receive either oral erlotinib or placebo. In the treated group overall survival was improved by 2 months (6.7 months $v$ 4.7 months, $\mathrm{p}<0.001)$. Factors predicting response to treatment were being a non-smoker, adenocarcinoma on histology, and expression of EGFR in biopsy specimens. Survival was not affected by EGFR receptor expression or EGFR mutations. This is the first study to demonstrate a survival advantage with an oral tyrosine kinase inhibitor of EGFR. Further studies investigating the use of these agents in early lung cancer are now warranted.

N Goldsack

Consultant Chest Physician, East Kent Hospitals NHS Trust, UK 